\title{
The Effect of Abdominal Breathing Exercise on Weight and Body Fat, BMl, Waist Hip Ratio in Obese College Student
}

Yi-Sub Kwak* and Young-II Kim ${ }^{1}$

Department of Physical Ecucation, Dongeui University, Busan 614714, Korea

${ }^{1}$ Department of Sports \& Health management, Youngsan University, Yangsan 120-749, Korea

Received October 27, 2010 /Accepted November 17, 2010

\begin{abstract}
The purpose of this study was to investigate the effects of 12 weeks of abdominal breathing exercises, through $\mathrm{AB}$ spur, on weight and $\mathrm{BMI} \%$ body fat, and waist-hip ratio in healthy college students. The subjects consisted of 20 obese young college students, and all of whom had no other health complications. The subjects were shown in detail the proper way to utilize the equipment and practice abdominal breathing in a laboratory setting. They were told to wear the AB spur for at least six hours a day in order to induce abdominal breathing exercise. Because the subjects were students, most of the abdominal breathing exercises took place while they were sitting in lectures at school, and they wore the equipment for 12 weeks. At 4, 8, and 12 weeks after the subjects started using the AB spur, there were significant decreases in weight, $\%$ body fat, BMI, and waist-hip ratio $(p<0.05)$. In conclusion, the results of the stud suggest that abdominal breathing exercise may be a good weight loss method, as well as a beneficial way to decrease obesity factors, in obese college students.
\end{abstract}

Key words : Abdominal breathing, exercise, obesity

\section{서 론}

비만률은 지난 10 년간 증가해오고 있으며 대략 미국인의 $66.3 \%$ 는 과 체중이거나 비만이라고 할 수 있다[15]. 건강에 좋지 않은 수많은 결과들은 비만과 제 2 형 당뇨(T2DM)와 관련 되어 있으며[14] 비만은 만성 대사질환 뿐만 아니라 정신적인 질환과 우울증을 수반한다[7]. 이렇듯 비만은 우리나라에서도 성인 뿐만 아니라 청소년 비만이 증가하는 추세에 있어 관심 이 주목되고 있다.

복식호흡은 횡격막의 강력한 수축에 의한 호흡법으로 비교 적 부작용이 없으며 지속적으로 사용할 수 있다. 또한 비침습 적이며 안전하고 경제적이며 운동 조절도 용이하여 일상생활 속에서 통합 할 수 있는 생리학적인 방법이다[8]. 이러한 복식 호흡은 숨을 깊고 크게 들이마셔 폐 밑에 위치한 횡격막을 아래로 밀어내고 이로 인해 배가 앞으로 나오면서 가슴에 부 분적인 진공상태를 만들면 그 자리에 공기가 들어오고 횡격막 이 제자리로 돌아오면서 공기를 배출하는 방법이다. 복식호흡 은 가장 쉬우면서도 전통적인 이완요법으로서 일명 횡격막 호흡이라고도 한다[11]. 이는 효과적으로 산소와 탄산가스를 교환시키며 동시에 이완을 증진시키는 방법이기도 하다[3].

복식호흡의 효과에 대한 국내 연구를 살펴보면 복식호흡이 스트레스 $[1,13,26]$ 와 면역반응[13] 그리고 임신부의 조기진통 $[2,5,23]$, 근육활성[12], 근 골격계 및 스포츠 분야의 치료방법

\section{*Corresponding author}

Tel : +82-51-890-1546, Fax : +82-51-890-2643

E-mail : ysk2003@deu.ac.kr
으로 소개되고 있으며[20] 다양한 분야에 긍정적인 영향을 미 쳤다는 연구가 있으며, 강 등은 운동시의 복식호흡은 혈중 생 화학변인과 생리 및 체력변인에 유의한 차이를 나타내지 못했 다고 보고하여[10] 아직까지 복식호흡에 대한 연구 효과들은 다각적 시각에서의 재조명이 필요한 것으로 사료된다.

현재까지 복식호흡이 인체의 스트레스 및 면역반응[13], 요 통[12], 임산부 불안[2,5,23] 등 심신의 이완에 긍정적인 영향을 미친다는 결과는 있지만 체중감소에 관련한 연구는 미비한 상태이다.

따라서 본 연구는 건강한 성인 20명(남 3, 여17)을 대상으로 $\mathrm{AB}$ spur를 착용하고 12주 복식호흡 운동을 함에 따라 신체적 특성 및 체지방률(\% body fat), 체질량지수(BMI), 복부 비만률 (Waist/Hip ratio)의 변화를 알아보고 복식호흡이 비만판정과 관련된 요소에 미치는 영향을 분석하는 것에 목적이 있다.

\section{재료 및 방법}

\section{연구대상}

본 연구의 대상자는 모두 D 대학교에 재학중인 대상자(총 20명; 남:3, 여:17)들로 문진을 통하여 사전과 현재 병력을 조사 하여 의학적으로 질환이 없는 대상자로 구성하였다. 이들의 신체적 특성은 Table 1에 나타나 있다.

\section{$\mathrm{AB}$ spur 착용 및 복식호흡 방법}

실험실에서 사용방법과 숙지사항을 자세히 설명하고 각 개 인마다 장비를 착용하여 20 분간 체험을 실시하였다. 복식호흡 
Table 1. The difference of physical characteristic

\begin{tabular}{lcccccc}
\multicolumn{1}{c}{ Variable } & Pre & 4 wk & 8 wk & 12 wk & F-value & P-value \\
\hline Age $(\mathrm{yr})$ & 23 & - & - & - & - & - \\
Height $(\mathrm{cm})$ & $164.7 \pm 7.6$ & - & - & - & - & - \\
Weight $(\mathrm{Kg})$ & $58.0 \pm 9.5$ & $57.6 \pm 9.4^{\mathrm{a}}$ & $57.1 \pm 9.4^{\mathrm{b}}$ & $56.6 \pm 9.4^{\mathrm{c}}$ & 52.042 & $<0.05^{*}$ \\
BMI $\left(\mathrm{Kg} \cdot \mathrm{m}^{-2}\right)$ & $21.3 \pm 2.0$ & $21.1 \pm 1.9^{\mathrm{a}}$ & $20.9 \pm 1.9^{\mathrm{b}}$ & $20.8 \pm 1.9^{\mathrm{c}}$ & 43.042 & $<0.05^{*}$ \\
Fat $(\%)$ & $25.9 \pm 5.1$ & $25.6 \pm 5.0^{\mathrm{a}}$ & $25.0 \pm 5.0^{\mathrm{b}}$ & $24.5 \pm 4.9^{\mathrm{c}}$ & 38.406 & $<0.05^{*}$ \\
Waist hip ratio $(\mathrm{cm})$ & $0.81 \pm 0.04$ & $0.80 \pm 0.04^{\mathrm{a}}$ & $0.79 \pm 0.03^{\mathrm{b}}$ & $0.78 \pm 0.04^{\mathrm{c}}$ & 44.137 & $<0.05^{*}$ \\
\hline
\end{tabular}

Values are mean \pm S.D.

a: significantly different between pre and $4 \mathrm{wk}$

b: significantly different between pre and $8 \mathrm{wk}$, and $4 \mathrm{wk}$ and $8 \mathrm{wk}$

c: significantly different between pre and $12 \mathrm{wk}, 4 \mathrm{wk}$ and $12 \mathrm{wk}$

방법은 크게 들이쉬기(2 3초), 숨정지(1 2초), 내쉬기(약 4 5 초) 순서로 한다. 정확한 호흡을 유도하기 위하여 $\mathrm{AB}$ spur를 착용하고 Fig. 1, 숨을 들어마시며 복부를 최대한 내밀어준다. 그후 복부가 팽창되며 미세한 진동이 발생하는데, 이 진동을 각 피험자가 느껴야만 올바른 복식호흡으로 간주한다.

본 장비는 기상직후 착용하여 하루 6 시간, 12 주간 매일 착 용하게 하여 복식호흡 운동을 유도하였다. 실험대상자가 학 생들이기 때문에 대부분의 복식호흡 유도를 학교에서 강의 를 들을 때나 공부할 때, 앉은 상태에서 의도적으로 실시하 였다. 실험대상자는 본 운동 이외의 다른 어떠한 운동도 수 행하지 않게 하였고 연구기간은 총 12 주로 4 주, 8 주 와 12 주 에 체중, 체지방률, 체지량지수(BMI), 복부 비만율(W/R ratio)을 측정하였다.

신체계측 및 체지방률, BMl, Waist hip ratio 측정방법 체지방률(\% body fat) 측정은 체지방 측정계(InBody 720, biospace, Korea)를 사용하여 생체전기저항법(BIA)로 측정하 였고 체질량 지수 $(\mathrm{BMI})$ 는 신장과 체중을 측정하여 체중 $(\mathrm{kg})$ 을 신장 $(\mathrm{m})$ 의 제곱으로 나눈 값을 사용했다. 요위 $(\mathrm{WC})$ 와 둔위 $(\mathrm{HC})$ 를 측정하여 요위 대 둔위비율(WHR)을 구하였다.

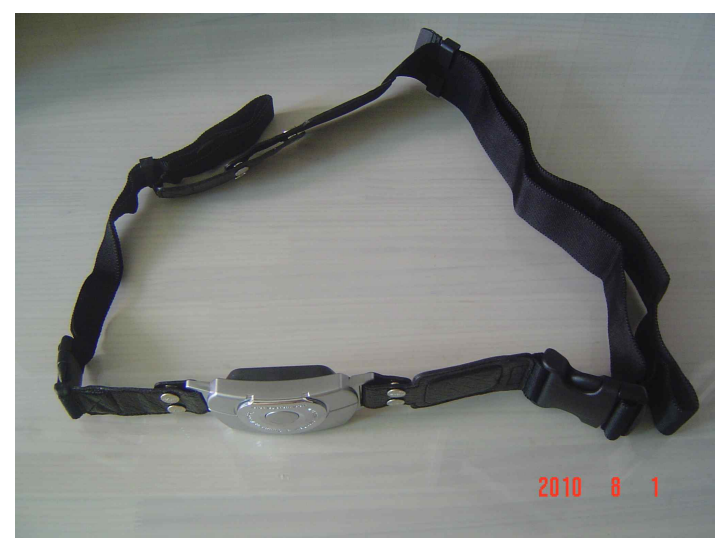

Fig. 1. $\mathrm{AB}$ spur equipment.

\section{자료처리}

본 연구에서는 SPSS/PC Windows 12.0으로 각 집단별의 신체적 특성, 복부 비만율 및 안정시 대사량에 대한 결과를 평균(means)과 표준편차(standard deviation)로 표시하였다. 또한 4 주, 8 주, 12 주간 변화를 알아보기 위해 One-way$\mathrm{ANOVA}$ 를 통해 유의한 차이 $(p<0.05)$ 를 분석하였다.

\section{결과 및 고찰}

대상자의 신체적 특성 및 체중, 체지방률, $\mathrm{BMl}$, 복부비만 율의 변화

나이와 신장을 제외한 체중, 체질량지수(BMI), 체지방률 (\%body fat)과 복부비만율( $\mathrm{W} / \mathrm{H}$ ratio)은 복식호흡 운동 전에 비해 4 주, 8 주 12 주 모두 유의한 차이 $(p<0.05)$ 를 나타내었다 (Fig. 2-5). 복식호흡의 효과는 여러 선행연구의 다양한 실험에 서 긍정적인 결과로 나타났다 $[5,7,12,13,23,26]$. 복식호흡 운동 은 어떤 기능적인 재료를 원하지 않으며 느리게 코로 깊숙이 흡기하고 의도적으로 아랫배 부분을 내밀어 공기가 하단전 깊숙이 들어가도록 하고 내쉴 때에는 입과 코를 통하여 밖을 내쉬면서 아랫배를 의도적으로 쑥 들어가게 하는 호흡법이다 [1]. 이러한 호흡법은 횡격막을 주로 사용하며 계속적으로 복 부에 자극을 준다. 또한 복식호흡이 스트레스와 면역반응[13],

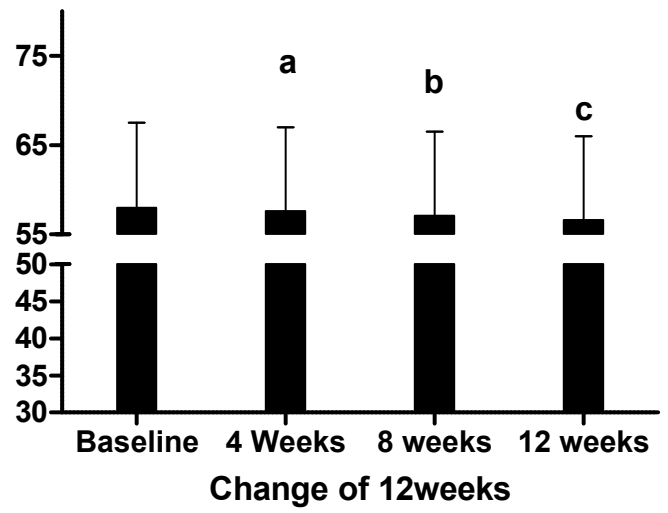

Fig. 2. The change of body weight measurement during $12 \mathrm{wk}$. 


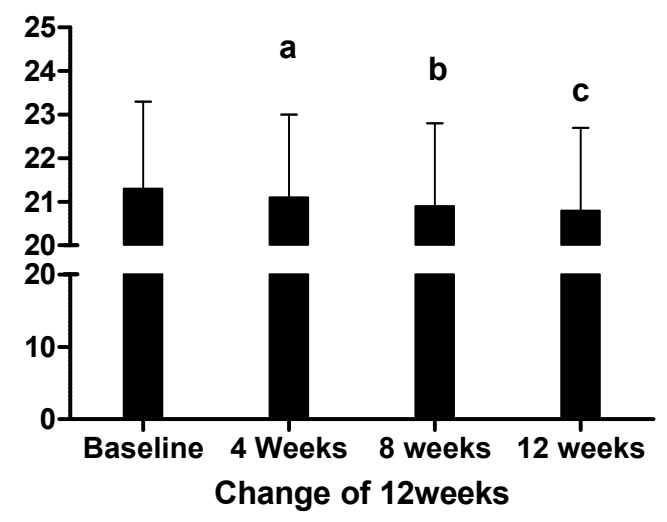

Fig. 3. The change of BMI measurement during $12 \mathrm{wk}$.

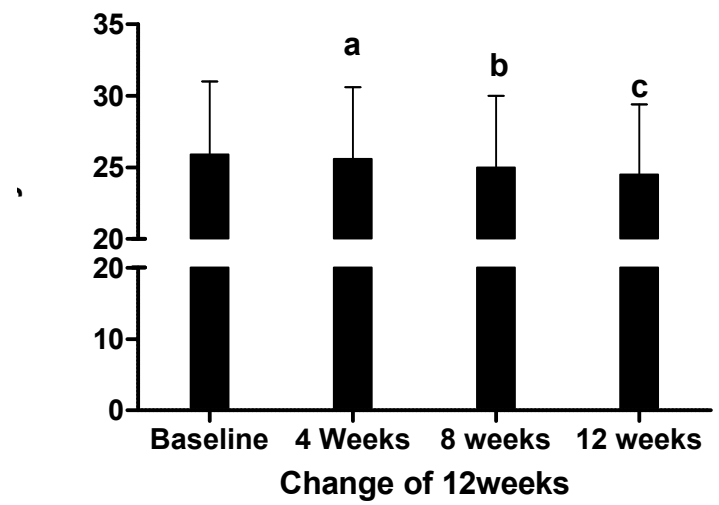

Fig. 4 . The change of $\%$ body fat measurement during 12 wk.

혈압강하[26]에 긍정적 반응을 보인 점과 특히 임산부의 불안 요소 $[2,5,23]$ 에 영향을 미쳐 이완요법으로의 효과를 나타냈다.

호흡운동과 관련된 연구를 살펴보면 관상동맥수술환자 (coronary artery bypass grafting, CABG)에서 깊은 호흡(deep breathing) 운동은 총폐활량(total lung capacity, TLC)을 증가 시키며[18], 산소공급을 증가시키고 $\mathrm{FVC}_{\text {와 }} \mathrm{FEV}_{1}$ 을 유의하게 증가시켜 폐 기능을 증가시켰다고 보고하였다[25]. 또한 비만 자에 있어 저환기신드롬(obesity hypoventilation syndrome, $\mathrm{OHS}$ )과 수면호흡장애가 문제시되고 있으며[17] 체중감소로 인한 호흡기능(호흡근의 근력과 수행력)은 증가되었지만[24] 호흡기능의 증가가 어떤 메커니즘에 의해 체중감소에 영향을 미쳤는지는 언급되지 않았다.

미주신경(vagus nerve)은 인두, 후두뿐만 아니라 경부, 흥 부, 복부 내장에 까지 광범위하게 분포하며 미주신경은 부교 감신경으로 특히 심장에 대해 억제적으로 작용하여 심박수를 감소시키고 수축력을 감소시키는 작용을 한다[9]. 복식호흡은 이러한 이유로 스트레스와 불안을 감소시키는 이완(relax)작 용을 담당하는 미주신경과 밀접한 관련이 있다고 생각된다.

운동과 다이어트를 동반하지 않고 미주신경 만을 자극하여 체중감소를 유도한 Pardo 등의 연구에서는 격렬한 비만자 14 명의 대상으로 꾸준한 6-12개월 미주신경 자극(vagus nerve

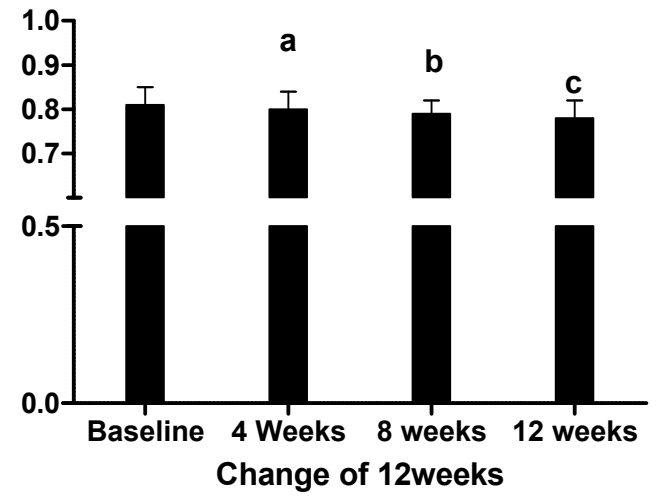

Fig. 5. The change of waist hip ratio measurement during 12 wk.

stimulation, $\mathrm{VNS}$ )을 실시하여, 대상자들의 평균 체중감소가 1 년에 $7 \mathrm{~kg}$ 이었고 $\mathrm{BMI}$ 의 경우에는 $2 \mathrm{~kg} / \mathrm{m}^{2}$ 감소를 나타냈다 [16]. 이는 안정적인 기분상태 $(\mathrm{mood})$ 가 식사를 과식하지 않도 록 하는 것과 관계가 있다고 보고하였고[16], 동물의 연구에서 는 식이행동과 체중관련에서 미주신경자극 효과의 증거를 제 공하였으며, VNS therapy는 비만의 궁극적인 치료에 흥미로 운 것으로 드러났다[6,21]. 이전의 연구에서 제안되는 것은 장 기간의 VNS therapy는 개인적인 우울증상을 TRD를 통해 저 하시키는 것에 효과가 있는 것으로 나타났다[20,21].

본 연구의 결과 4 주, 8 주, 12 주까지 체중 및 체지방률 $(\%$ body fat), 체질량지수(BMI), 복부 비만률(W/H ratio)은 모두 유의하게 $(p<0.05)$ 감소된 것으로 나타났다. 이러한 결과는 이 전의 선행연구들에서 밝혀졌듯이 미주신경 자극(vagus nerve stimulation, VNS)이 체중감소를 유발하고, 복식호흡이 미주 신경 분포와 자극에 밀접한 관련[6,16,21]이 있는 것으로 보아 결과적으로 복식호흡이 미주신경을 자극하여 체중 및 체지방 률(\% body fat), 체질량지수(BMI), 복부 비만률(W/H ratio) 감소에 영향을 미친 것으로 사료된다.

하지만 본 연구의 제한점으로는 복식호흡 자체가 비만관련 인자의 감소에 얼마나 많은 영향을 주었는가를 명확히 증명할 수는 없었던 점이며, 이는 추후 연구(식이 및 식단의 명확한 제시와 통제 및 생화학 분석)를 통해 보완하고자 한다.

\section{감사의 글}

이 논문은 동의대학교 교내 일반연구과제에서 지원받아 수 행되었습니다. 이에 깊은 감사 드립니다(2009AA225).

\section{References}

1. An, J. D. 2003. The effect of taekwondo player's stress decrease on abdominal breathing and meditation program. $J$. Korean Soc. Study Phy. Edu. 8, 172-187. 
2. An, S. E. 2008. Effect of abdominal breathing on anxiety and labor time in primipara women. Korean J. Wom Heal. Nurs. $14,196-204$.

3. Benson, H. 1975. The relaxation response. NY: William Morrow \& Co.

4. Bodenlos, J. S., S. Kose, J. J. Borckardt, Z. Nahas, O'Neil. PM. Shaw, S. L. Pagoto, and M. S. George. 2007. Vagus nerve stimulation and emotional responses to food among depressed patients. J. Diabetes. Sci. Technol. 1, 771-779.

5. Chang, S. B., H. S. Kim, Y. H. Ko, C. H. Bae, and S. E. An. 2009. Effect of abdominal breathing on anxiety, blood pressure, peripheral skin temperature and saturation oxygen of pregnant women in preterm labor. Korean J. Wom Heal. Nurs. 15, 32-42.

6. Cigaina, V. 2002. Gastric pacing as therapy for morbid obesity: preliminary results. Obes. Surg. 12, 12S-16S.

7. Fitzgibbon, M. L., M. R. Stolley, and D. S. Kirschenbaum. 1993. Obese people who seek treatment have different characteristics than those who do not seek treatment. Health Psychol. 12, 342-345.

8. Fried, R. 1986. The hyperventilation syndrome: research \& clinical treatment. Baltimore, The Johns Hopkins Univ press.

9. Jung, I. K. and J. W. Yoon. 2006. Human performance \& exercise physiology. pp. 187, 3th eds., Dae Kyong books. Seoul.

10. Kang, S. J., S. Y. An, B. S. Sin, Y. E. Choi, J. Y. Youn, B, H. Lee, C. K. Kim, J. S. Yang, and B. W. Joe. 1987. Effect of performance on danjeon breathing and oriental medicine administration. J. Korean Fitn. Sci. 2, 1-21.

11. Kim, G. S. and Y. H. Song. 1993. Relaxation therapy for pain control. Korean Acad Craniomandibular Disorders 5, 1-5.

12. Kim, K. 2006. Effect of diaphragmataic breathing on activation of trunk muscle of normal healthy people. Korean Spor. Resear. 17, 545-554.

13. Kim, K. S., S. W. Lee, M. A. Choe, M. S. Yi, S. Choi, and S. H. Kwon. 2005. Effect of abdominal breathing using biofeedback on stress, immune response and quality of life in patients with a mastectomy for breast cancer. J. Korean Acad Nurs. 35, 1295-1303.

14. Mokdad, A. H., E. S. Ford, B. A. Bowman, W. H. Dietz, F. Vinicor, V. S. Bales, and J. S. Marks. 2003. Prevalence of obesity, diabetes, and obesity-related health risk factors, 2001. JAMA 289, 76-79.

15. Ogden, C. L., M. D. Carroll, L. R. Curtin, M. A. McDowell, C. J. Tabak, and K. M. Flegal. 2006. Prevalence of overweight and obesity in the United States, 1999-2004. JAMA 295, 1549-1555.
16. Pardo, J. V., S. A. Sheikh, M. A. Kuskowski, C. SurerusJohnson, M. C. Hagen, J. T. Lee, B. R. Rittberg, and D. E. Adson. 2007. Weight loss during chronic, cervical vagus nerve stimulation in depressed patients with obesity: an observation. Int. J. Obes. 31, 1756-1759.

17. Piper, A. J. and R. R. Grunstein. 2010. Big breathing: the complex interaction of obesity, hypoventilation, weight loss, and respiratory function. J. Appl. Physiol. 108, 199-205.

18. Renault, J. A., R. Costa-Val, M. B. Rosseti, and M. H. Neto. 2009. Comparison between deep breathing exercises and incentive spirometry after CABG surgery. Rev. Bras. Cir. Cardiovasc. 24, 165-172.

19. Roslin, M. and M. Kurian. 2001. The use of electrical stimulation of the vagus nerve to treat morbid obesity. Epilepsy Behav. 2, S11-S16.

20. Rush, A. J., H. A. Sackeim, L. B. Marangell, M. S. George, S. K. Brannan, S. M. Davis, P. Lavori, R. Howland, M. A. Kling, B. Rittberg, L. Carpenter, P. Ninan, F. Moreno, T. Schwartz, C. Conway, M. Burke, and J. J. Barry. 2005. Effects of 12 months of vagus nerve stimulation in treatment-resistant depression: a naturalistic study. Biol. Psychiatry 58, 355-363.

21. Rush, A. J., L. B. Marangell, H. A. Sackeim, M. S. George, S. K. Brannan, S. M. Davis, R. Howland, M. A. Kling, B. R. Rittberg, W. J. Burke, M. H. Rapaport, J. Zajecka, A. A. Nierenberg, M. M. Husain, D. Ginsberg, and R. G. Cooke. 2005. Vagus nerve stimulation for treatment-resistant depression: a randomized, controlled acute phase trial. Biol. Psychiatry 58, 347-354.

22. Segal, N. A., J. Hein, and J. R. Basford. 2004. The effect of Pilates training on flexibility and body composition. Arch Phys. Med Rehabil. 85, 1977-1981.

23. Shim, J. O. and S. B. Chang. 2006. Effect of abdominal breathing on preterm labor anxiety. Korean J. Wom Heal. Nurs. 12, 106-114.

24. Weiner, P., J. Waizman, M. Weiner, M. Rabner, R. Magadle, and D. Zamir. 1998. Influence of excessive weight loss after gastroplasty for morbid obesity on respiratory muscle performance. Thorax. 53, 39-42.

25. Westerdahl, E., B. Lindmark, T. Eriksson, O. Friberg, G. Hedenstierna, and A. Tenling. 2005. Deep-breathing exercises reduce atelectasis and improve pulmonary function after coronary artery bypass surgery. Chest 128, 3482-3488.

26. Yu, S. J. and M. S. Song. 2001. The effects of abdominal relaxed breathing training on stress response and blood pressure for elderly hypertension patient. J. Korean Acad Nurs. 31, 998-1011. 
초록 : 복식호흡 운동이 비만 대학생의 체중, 체지방률, $\mathrm{BMl}$, 복부 비만률에 미치는 영향

곽이섭 $*$ 김영일 ${ }^{1}$

(동의대학교 체육학과, ${ }^{1}$ 영산대학교 스포츠건강관리학과)

본 연구는 건강한 성인을 20 명을 대상으로 $\mathrm{AB}$ spur를 착용하고 12 주 복식호흡 운동을 함에 따라 신체적 특성 및 체지방률(\% body fat), 체질량지수(BMI), 복부 비만율(Waist/Hip ratio)의 변화를 검증하여 비만과 관련되어 복식호흡의 중요성 강조 및 비만관련 인자 감소에 있어 기초자료로 제공하려는데 목적이 있다. 본 연구의 대상자 는 모두 D 대학교에 재학중인 대상자(총 20명; 남: 3 명, 여: 17명)들로 문진을 통하여 사전과 현재 병력을 조사하여 의학적으로 질환이 없는 대상자로 구성하였다. 본 연구를 수행하기 위해 복식호흡기기를 이용한 복식호흡훈련을 충분히 숙지 시킨 후에 하루 6시간, 12 주간 매일 착용하게 하였다. 복식호흡 방법은 크게 들이쉬기(2 3초), 숨 정지(1 2초), 내쉬기(약 4 5초) 순서로 하였으며, 정확한 호흡을 유도하기 위하여 $\mathrm{AB}$ spur를 착용하고, 숨을 들어 마시며 복부를 최대한 내밀어준다. 본 연구결과 12 주 복식호흡 훈련은 체중 및 체지방률, BMI, 복부 비만도를 유의하게 $(p<0.05)$ 감소시켰고 이는 비만과 관련하여 의미 있는 결과라 사료된다. 추후 운동과 더불어 비만자에 있어 이러한 복식호흡의 중요성을 강조하면 비만에 따른 체중 및 체지방 감소에 보다 효과적인 방법을 제시할 수 있을 것으로 사료된다. 